\title{
Characterization of GPS-TEC in a low-latitude region over Thailand during 2010-2012
}

\author{
V. Rajesh Chowdhary ${ }^{\star}$, N. K. Tripathi, Sanit Arunpold, Durairaju Kumaran Raju
}

Asian Institute of Technology, School of Engineering and Technology, Klong Laung, Pathumthani, Thailand

\author{
Article history \\ Received December 26, 2014; accepted September 22, 2015. \\ Subject classification: \\ Ionosphere, Total electron content, Solar cycle, GPS-TEC, IRI-2007, IRI-2012, GPS SCINDA, IGS.
}

\section{ABSTRACT}

This paper presents the first results of vertical total electron content (VTEC) data from (1) a dual-frequency GPS receiver installed at the Chiang Mai University in Chiang Mai (CHGM, 18.480 N, 98.570 E) as part of SCINDA (Scintillation Network and Decision Aid) and (2) the International GNSS Service (IGS) station Pathum Wan (CUSV, 13.735 N, $100.533 \mathrm{E}$ ) with magnetic latitude of $8.69^{\circ} \mathrm{N}$ and $3.92^{\circ} \mathrm{N}$ respectively in Thailand, from August 2010 to July 2012. In the equatorial ionization anomaly (EIA) region, these two stations are separated at a distance of $668 \mathrm{~km}$. Observed GPS-TEC values were found to be the highest between 1500 and 1900 Local Time (LT) throughout the study period at both the stations. The GPS-TEC data from both the stations was plotted diurnal, monthly and seasonal analyses were performed. The equinox (March, April, September, and October) and solstice (January, February, June, July, and December) periods had maximum and minimum diurnal peak variations, respectively, of the GPS-TEC. High TEC values are attributed to extreme solar ultra-violet ionization coupled with upward vertical $E \times B$ drift. A comparison of the GPS-TEC data from both the stations for the study period shows that the CHGM station recorded higher values of TEC than the CUSV station because of the formation of an ionization crest over the CHGM station. The GPS-TEC values also exhibited an increasing trend-because of the approach of solar cycle 24. For data validation, the diurnal, monthly, and seasonal variations in the measured TEC were compared with the TEC modelled in the International Reference Ionosphere (IRI) models (IRI-2007 and the recently released IRI-2012 model). The IRI-2007 shows good agreement with the data from 2010 to 2011 from both stations and IRI-2012 agrees well with the data from 2012 onwards compared to IRI-2007.

\section{Introduction}

Recently, Global Navigation Satellite System (GNSS) has played a vital role in research involving atmospheric sensing worldwide. GNSS has been widely used to determine the perceptible water vapour (PWV), zenith tropospheric delay (ZTD), vertical total electron content (VTEC) across the various locations of the Earth. In addition to IGS stations, many independent GNSS networks have evolved with time, leading to the availability of large datasets across the globe. One such network, Scintillation Network and Decision Aid (SCINDA) was established by the Air Force Research laboratory of USA, as a set-up of ground based stations that monitor trans-ionospheric signals at the VHF and L Band frequencies. Main purpose of SCINDA is to serve as regional specification and short term forecasts of scintillation occurring onto VHF and L Band frequencies i.e., especially on communication and navigation signals. The SCINDA ground stations are generally positioned between the equatorial ionization anomaly (EIA) region, as these locations experience the strongest global levels of scintillation [Carrano and Groves 2006]. The EIA is characterized by a trough at the geomagnetic equator and two peaks (crests) on either side of the equator about $15^{\circ}$ magnetic latitude [Appleton 1946]. The equatorial anomaly forms when vertical drift velocities push the F-region plasma to the higher heights over the equatorial region. Pressure gradients and gravity force the uplifted plasma downwards and outwards along the magnetic field lines, leading to highly variable drift velocities [D'ujanga et al. 2012]. EIA's expansion and variations in electron density is reflected in the GPS-TEC as the F-region forms the largest part of TEC [Olwendo et al. 2012]. Thus, adding to an ample scope of studying EIA patterns during diurnal, seasonal, annual, solar cycle dependent period in a wide range of time scales.

The total electron content (TEC) of the ionosphere is known as the summation of free electrons present in a unit area column of ionosphere from the ground to a height well above the ionization crest. This TEC is typically expressed as a vertical column $1 \mathrm{~m}^{2}$ in area. The parameters which influence TEC are solar extreme ultra-violet flux, geographic location, local time, season, and geomagnetic activities. It has been proven experimentally that, TEC is comparatively easy parameter to 
measure. The first results of TEC were obtained during late 1950s, showed the first temporal and seasonal, characteristics of the topside ionosphere. The key scientific value of TEC today, lies in its ease of calculation, given the availability of satellite source. During the magnetically disturbed periods, TEC can provide continuous F-region measurements. TEC measurements can be used as another regular parameter for defining the F2 region at various locations. Any communication system which involves propagation of radio waves through the ionosphere and which requires time delay measurements to an accuracy of the same order as the ionosphere time delay errors needs the knowledge of TEC to do error corrections. The ionosphere causes delay in the velocity of the information carried on a radio wave called group path delay. This group path delay generates timing errors in radar and navigation systems which traverse through the ionosphere. The group path delay timing error is directly proportional to the TEC . The TEC measured along the line of sight of the satellite signal, called the slant TEC, is converted to the vertical TEC at the Ionospheric Pierce Point (IPP) i.e., the points where the ray paths intersect the shell model of the ionosphere. The vertical TEC (vTEC) is considered a more robust parameter to characterize the TEC over a given receiver position. TEC acts as a good indicator for the geographical distribution of the ionization of the Earth's ionosphere. A significant number of research studies has been carried out on the variations of TEC diurnally, seasonally and annually in low-latitude, high-latitude and equatorial region [Ezquer et al. 2004, Mendes da Costa et al. 2004, Chauhan and Singh 2010, Luhr and Xiong 2010, Xu et al. 2012, Correia et al. 2013, Spogli et al. 2013, Arunpold et al. 2014]. Many researchers have compared the results of GPS-TEC data obtained from diverse resources at several locations with various models, such as the IRI models [Bilitza et al. 1998, Jakowski et al. 1998, Huang and Reinisch 2001, Jodogne et al. 2004, Mosert et al. 2004, Olwendo et al. 2012, Chowdhary et al. 2015].

\section{Materials and methods}

\subsection{GPS TEC data}

This work covers the period from August 2010 to July 2012, two years of increasing solar activity. The data used have been recorded by a NoVatel GPS receiver (model GSV 4004B) installed by the SCINDA project in Chiang Mai University, (CHGM, $18.480 \mathrm{~N}$, $98.570 \mathrm{E})$, Thailand. Due to the dispersive medium of the ionosphere, the trans-ionospheric radio waves experience group delays and phase advances which are proportional to the TEC. TEC is defined as a measure of the total number of electrons in a cylinder with a cross section of $1 \mathrm{~m}^{2}$ centered on the line of sight from the transmitter on a satellite to a terrestrial receiver [Bhuyan and Borah 2007]. TEC arising from the group delay form pseudorange measurement can be expressed as [Opperman et al. 2007].

$$
\mathrm{TEC}_{\text {group }}=\frac{1}{40.3}\left(\frac{1}{f_{1}^{2}}-\frac{1}{f^{2}}\right)^{-1}\left(\mathrm{P}_{1}-\mathrm{P}_{2}\right)
$$

where $f_{1}^{2}$ and $f_{2}^{2}$ are L1 and L2 carrier frequencies, and $\mathrm{P}_{1}$ and $\mathrm{P}_{2}$ are pseudo-range observable, respectively. TEC from carrier phase measurement is given by

$$
\mathrm{TEC}_{\text {phase }}=(\mathrm{C} 1-\mathrm{C} 2) 2.852
$$

where $\mathrm{C} 1$ and $\mathrm{C} 2$ are phase measurements in nano seconds.

Group delay measurements of TEC computations are absolute and noisy. The relative phase delay between the two carrier frequencies gives a more precise measure of relative TEC, but is ambiguous because the actual number of cycles of phase is unknown. These two estimates can be combined to form an improved estimate of the absolute TEC [Opperman et al. 2007]. The resultant absolute TEC is the so-called GPS-derived slant TEC (sTEC) along the signal path between satellite and receiver. The slant TEC calculated along the oblique signal paths are mapped to vertical TEC (VTEC) values by means of the Single Layer Model as shown in the equation:

$$
\text { VTEC }=\left[\operatorname{sTEC}-\left(B_{R}-B_{S}\right)\right] / M(\varepsilon, h)
$$

where $B_{R}$ is the receiver bias, $B_{S}$ is the satellite bias and $\mathrm{M}(\varepsilon, \mathrm{h})$ is the single layer mapping function of the ionosphere defined as

$$
M(\mathcal{E}, \mathrm{h})=\sec \left\{\arcsin \left[\frac{\mathrm{R}_{\mathrm{e}} \cos \varepsilon}{\mathrm{R}_{\mathrm{e}}+\mathrm{h}}\right]\right\}
$$

where $\mathrm{R}_{\mathrm{e}}$ is the Earth radius in $\mathrm{km}$ and $\varepsilon$ is the elevation angle in radians. Here $h$ is the ionospheric height which is assumed at $350 \mathrm{~km}$ [Dashora and Pandey 2005]. For this current research, the data post processing of the relative TEC as illustrated from Equations (1-4) was performed using the GPS TEC analysis application software developed by Seemala and Valladares [2008] of the Institute of Scientific Research for Boston College, USA.

\subsection{International Reference Ionosphere (IRI) model}

To establish an international standard for the specification of ionospheric parameters based on all worldwide available data from both satellite and ground 
station observations, the International Reference Ionosphere (IRI) project was initiated by the Committee on Space Research (COSPAR) and by the International Union of Radio Science (URSI) in the late 1960s. Its main goal was to build an empirical model to avoid the uncertainties developing in the theoretical understanding of ionospheric processes and coupling to the regimes below and above. The International Reference Ionosphere model, is an internationally accepted standard model for the measurement of ionospheric parameters (e.g., electron density, total electron content, electron and ion temperature, ion composition), which can be derived as a function of geographic location, time (LT or UT), height and sunspot number for magnetically quiet days. The IRI model has advanced over time and many significant enhancements have been made through the addition of data available from all the ground stations across the world as well as from satellite observations [Bilitza 2003].

Earlier, model inputs have been mostly from midlatitudes and the model estimates have explained the ionospheric factors from these regions very well. On the other hand, for equatorial and low mid-latitude regions, many researchers have stated non-compatibility of the earlier model versions. This is due to under or over estimation of TEC for these areas [Bhuyan and Borah 2007, Mosert et al. 2007, Scida et al. 2009]. The IRI-2007 version, for the first time included a model for the occurrence probability of spread $\mathrm{F}$, a characteristic observation which occurs near the magnetic equator during night time [Bilitza and Reinisch 2008]. The IRI2007 model has been verified in various equatorial and low latitude regions and a good concurrence, in certain parameters, has been recorded between modelled TEC and that acquired from both satellite measurements and ground based GPS receivers [Sethi et al. 2011, Adewale et al. 2012, Olwendo et al. 2012, Arunpold et al. 2014]. And recently IRI model was upgraded to IRI2012 version. This has come up with additional number of indices used by the model namely, 3-hour $\mathrm{A}_{\mathrm{p}}$-Index, daily $\mathrm{A}_{\mathrm{p}}$-Index, 3-h $\mathrm{K}_{\mathrm{p}}$-Index and F107_81D which is average of 81 days centered running mean Solar Radio Flux at $10.7 \mathrm{~cm}(2800 \mathrm{MHz})$. More information on the IRI project, including information on the IRI Newsletter and the IRI electronic mailer, can be found on the IRI homepage at http:// IRI.gsfc.nasa.gov/.

\subsection{International GNSS Service (IGS) TEC data}

International GNSS Service (IGS) monitors and maintains the IGS TEC data. The IGS consists of an international network of over 380 constantly operating dual frequency GPS stations. The Central Bureau for the service is situated at the Jet Propulsion Laboratory, which maintains the Central Bureau Information System (CBIS) and ensures admittance to IGS products and information. An international governing board oversees all aspects of IGS. The International Association of Geodesy approved the IGS service and acknowledged as a member of the Federation of Astronomical and Geophysical Data Analysis Services (FAGS) since 1994 and 1996 respectively. The IGS collects stores and dispenses the GPS observables data. It also provides the global TEC map data available on the internet, and these data can be accessed from the File Transfer Protocol (FTP) site: ftp:/ /igscb.jpl.nasa.gov/ .

In this research work, we utilized the daily data of IGS station available in Thailand. The code of IGS station located in Thailand is named as CUSV and its data can be accessed from the File Transfer Protocol (FTP) site: ftp: / / cddis.gsfc.nasa.gov/pub/gps / data/ daily. RINEX format files for the year 2010 to 2012 were downloaded from this site, and then they were post-processed by using GPS-TEC analysis application software as described in Section 2.1.

\section{Results and discussions}

3.1. Mean variation of the GPS TEC, TEC from the IRI2007 and IRI-2012 models during sunrise, midday, post sunset and midnight

Figure 1a,b shows the comparison between the diurnal mean values of GPS TEC, IRI-2007 and IRI-2012 (in TEC units of $10^{16} / \mathrm{m}^{2}=1 \mathrm{TECU}$ ) at Chiang Mai (CHGM) and CUSV stations from August 2010 to December 2010, a period of increasing solar activity. Each curve shows the variation of TEC versus the hours representing different times of the day, including $0000 \mathrm{UT}$ (+7 hours LT, sunrise), 0600 UT (midday), 1200 UT (post sunset) and 1800 UT (midnight) respectively. The black solid line denotes GPS TEC from the observation of the station, dotted red line is the IRI-2007 and dotted blue line is the IRI-2012 predictions respectively.

From Figure 1a it is inferred that both IRI models have shown good agreement with the GPS TEC data during 0000 UT. While for 0600 UT, models have overestimated TEC values than actual. For 1200 UT, IRI-2007 values were observed more than IRI-2012 and were in good agreement with GPS TEC data. But during 1800 UT i.e., 0100 LT both the models underestimated TEC values. From Figure $1 \mathrm{~b}$ it can be observed that similar trend has been followed by both model for CUSV station as well except $0000 \mathrm{UT}$ where underestimation is more prevalent than in the former case of CHGM. Thus from July-December 2010 data confirms that both the models have shown underestimation and overestimation during 0100 LT and 1300 LT for maximum 
VTEC Map at station: CHGM : 0000 UT,2010
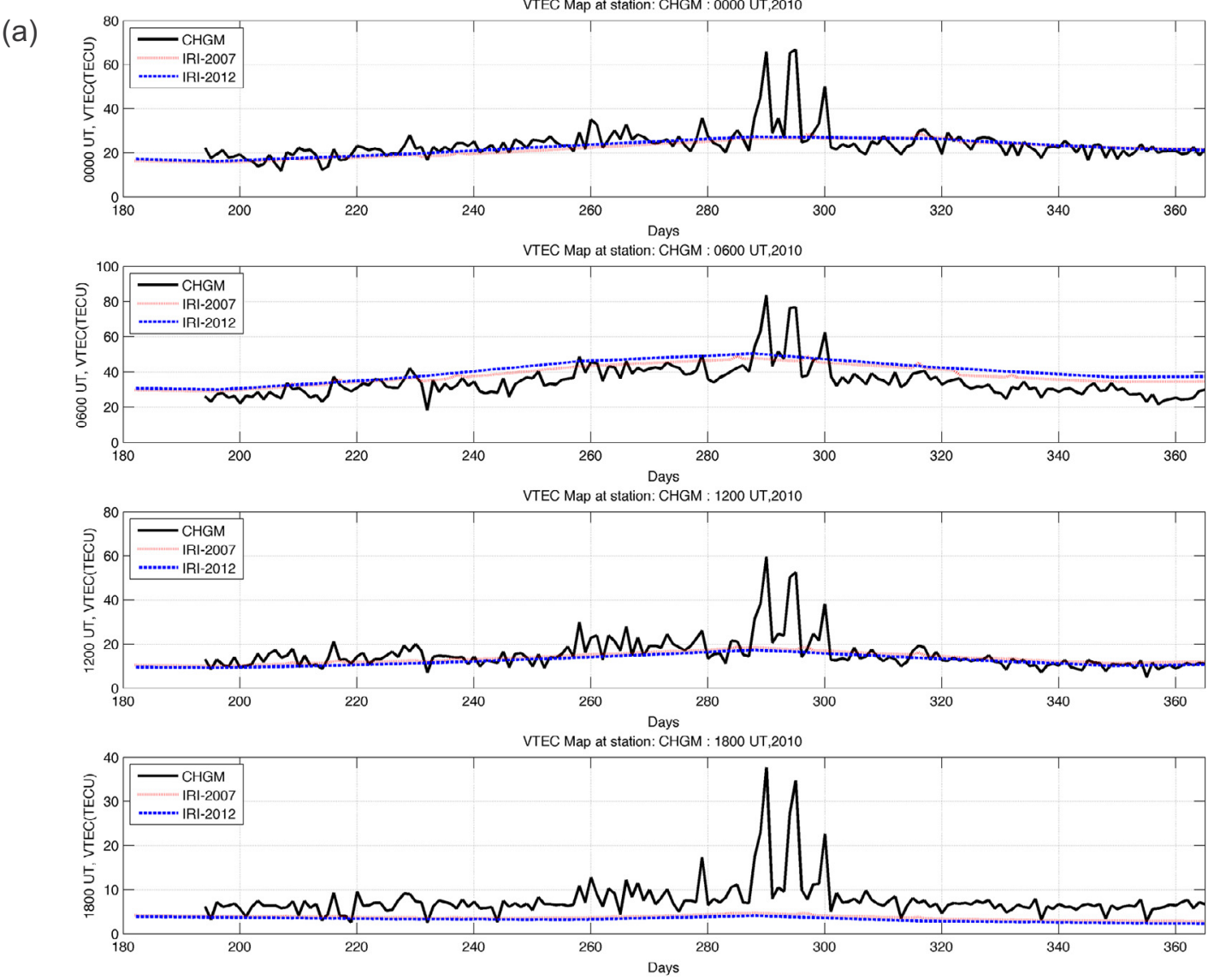

VTEC Map at station: CUSV : 0000 UT,2010

(b)
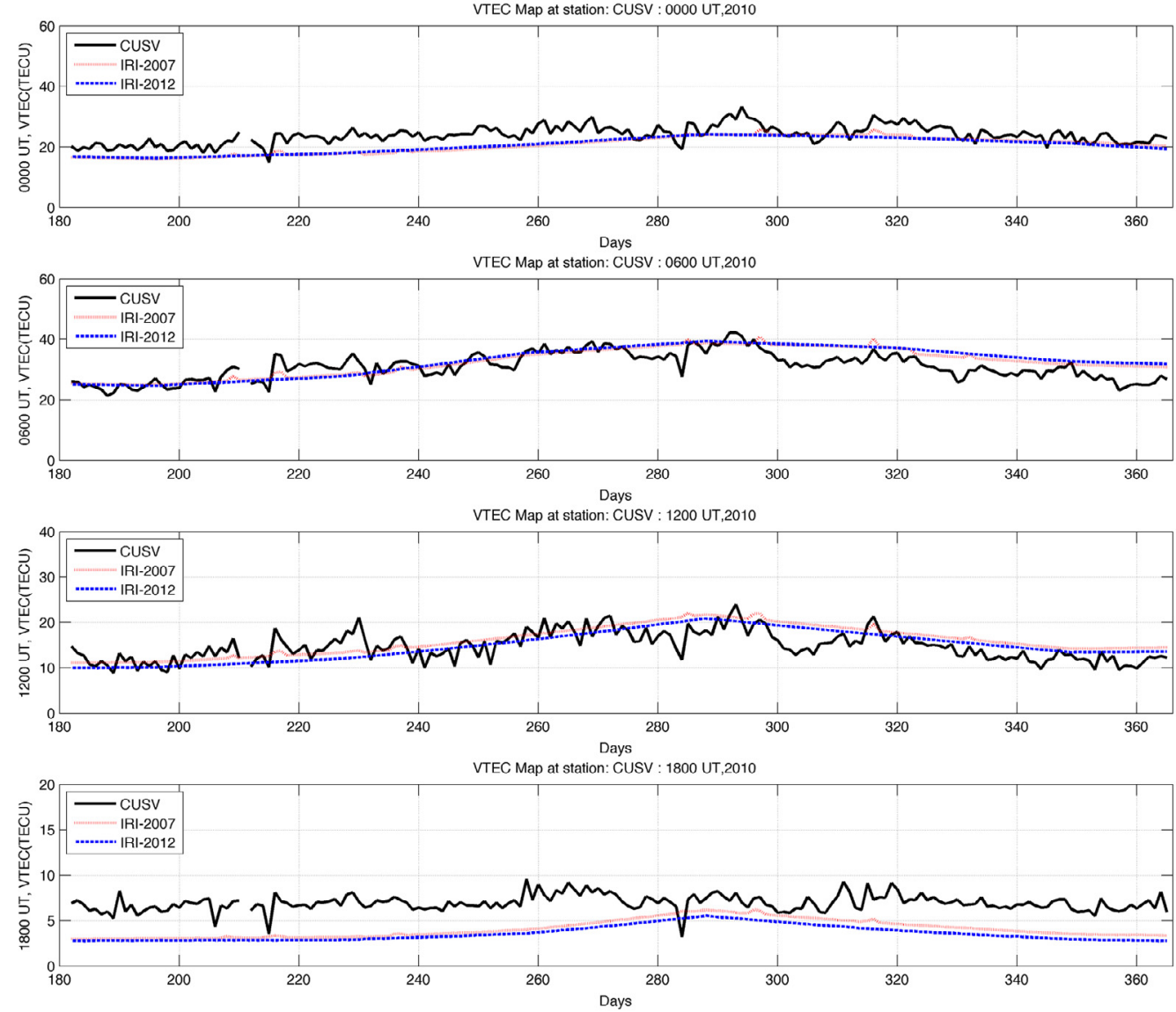

Figure 1. Mean variation of the GPS TEC, TEC from the IRI-2007 model and TEC from the IRI-2012 model, from August 2010 to December 2010 at CHGM and CUSV respectively during sunrise, midday, post sunset and midnight. 
number of days in the year for both stations. Also, maximum TEC values were recorded during 1300 LT from both GPS stations. A peak is quite evident during the 284th day for CHGM station which was due to geomagnetic storm on October 11, 2010, which was not predicted by both the models. This peak due to storm is not observed at CUSV station. Enhancements in TEC during night time were not predicted by the models which were predominant over CUSV than at CHGM station. Average highest diurnal TEC value observed from GPS-TEC was 51 and 40 TECU during noon time and lowest being 4 TECU during early morning hours for CHGM and CUSV respectively.

Figure 2a,b gives the comparison of GPS derived TEC with models derived values for the year 2011 for CHGM and CUSV respectively. It can be inferred that due to increase of solar activity and approaching of solar cycle 24 , the TEC values showed an increase. During sunrise both the models have shown good correlation with TEC data with CHGM station. In CUSV station, TEC values were observed more than predicted during equinox period during 0000 UT. But during noon time, both IRI-TEC values show underestimation and overestimation during equinox and solstice seasons, respectively for both stations. And for post sunset IRI-2012 has shown little underestimation whereas IRI-2007 has deviated much more than observed TEC. During midnight IRI-2012 model has shown good agreement with observed values than IRI-2007 model. Thus, it can be clearly seen that for 2011 data, both models have overestimated and underestimated during solstice and equinox respectively. The equinoctial months (March and April) have got particularly high TEC values greater than 60 TECU, whereas the solstice months (June and July) have maximum values that are lower than 40 TECU for CHGM and CUSV respectively. Later part of year 2011 experienced higher TEC during September equinox at both stations. In 2011, severe events were occurred during September and October which influenced the TEC values of CHGM and CUSV but were unpredicted by IRI models. A wave like trend can be observed from the plots, which gives a clear understanding of TEC characteristics. During 50-100 days TEC values increases and reach to a peak and then slowly decreases during 150200 days. This trend is due to the effect of seasonal variations on the Earth.

Figure 3a,b shows the data for the year 2012 for CHGM and CUSV respectively. From the plot it is clearly stated that TEC values observed from CHGM station has exhibited more compared to previous years and the average value during noontime has peaked from 51 TECU in 2010 to 80 TECU in 2012 respectively.
Same applied to CUSV as well, from 45 TECU in 2010 to 70 TECU in 2012 respectively. From Figure 3a,b it is observed that IRI-2007 model has totally failed to predict the right values for the TEC by predicting severe overestimation, whereas on the other hand IRI-2012 has been observed to be in good agreement with TEC data. Due to expected peak of solar cycle, the overall observed values of TEC have been increased and have become intense. Number of sunspots also increased, compared to previous year which also resulted in increase in number of severe events. TEC depletions and enhancements were observed during severe events dates. March 2012 was the most intense month of the whole study. Bhattacharya et al. [2009] studied the diurnal variation of the ionospheric time delay at Bhopal (lat $23^{\circ} 12^{\prime} \mathrm{N}$; lon $77^{\circ} 36^{\prime} \mathrm{E}$ ), an equatorial anomaly region, and reported that the diurnal variation was maximum during the equinoctial months. This is in agreement with our study since ionospheric time delay is directly proportional to TEC along the path of propagation.

\subsection{Seasonal comparison of GPS TEC, TEC from IRI} 2007 model and TEC from IRI 2012 model

\section{Chiang Mai station (CHGM):}

In this section we have presented the seasonal variations of TEC from July 2010 to August 2012 observed at the Chiang Mai station (CHGM) and Pathum Wan (CUSV) and compared those values with IRImodels. Figures 4 and 5 show the seasonal mean TEC comparison of GPS TEC with IRI-2007 and IRI-2012 models for CHGM station. Each year has been classified into four seasons, including the March equinox (February, March, April), June solstice (May, June, July), September equinox (August, September, October), and December solstice (November, December, January) respectively.

As per our chosen study period, for the year 2010, we have two seasons namely September equinox 2010 and December solstice 2010. As seen from the figure IRI-2007 underestimates the TEC during 0400 UT to 0800 UT for September equinox (SE) 2010. And IRI2012 has followed almost same trend with IRI-2007 but with a little less underestimation.

The overestimation of IRI-TEC is being more evident at daytime than at night time. During December solstice (DS) 2010, an overestimation by both models during 0800 UT - 1400 UT was clearly evident.

From Figure 5 it is clearly visible that both models have underestimated TEC during post sunset time of March equinox (ME) 2011. For June solstice (JS) 2011, both models have exhibited overestimation during 10 UT- 22UT i.e., from sunset to sunrise. Thus from the 


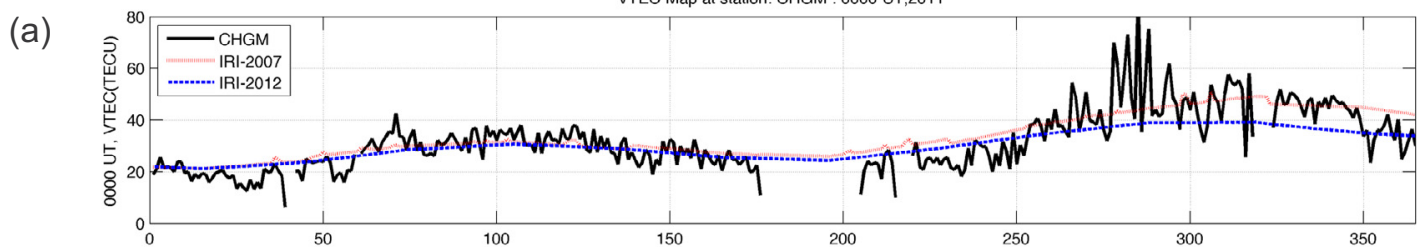

Days
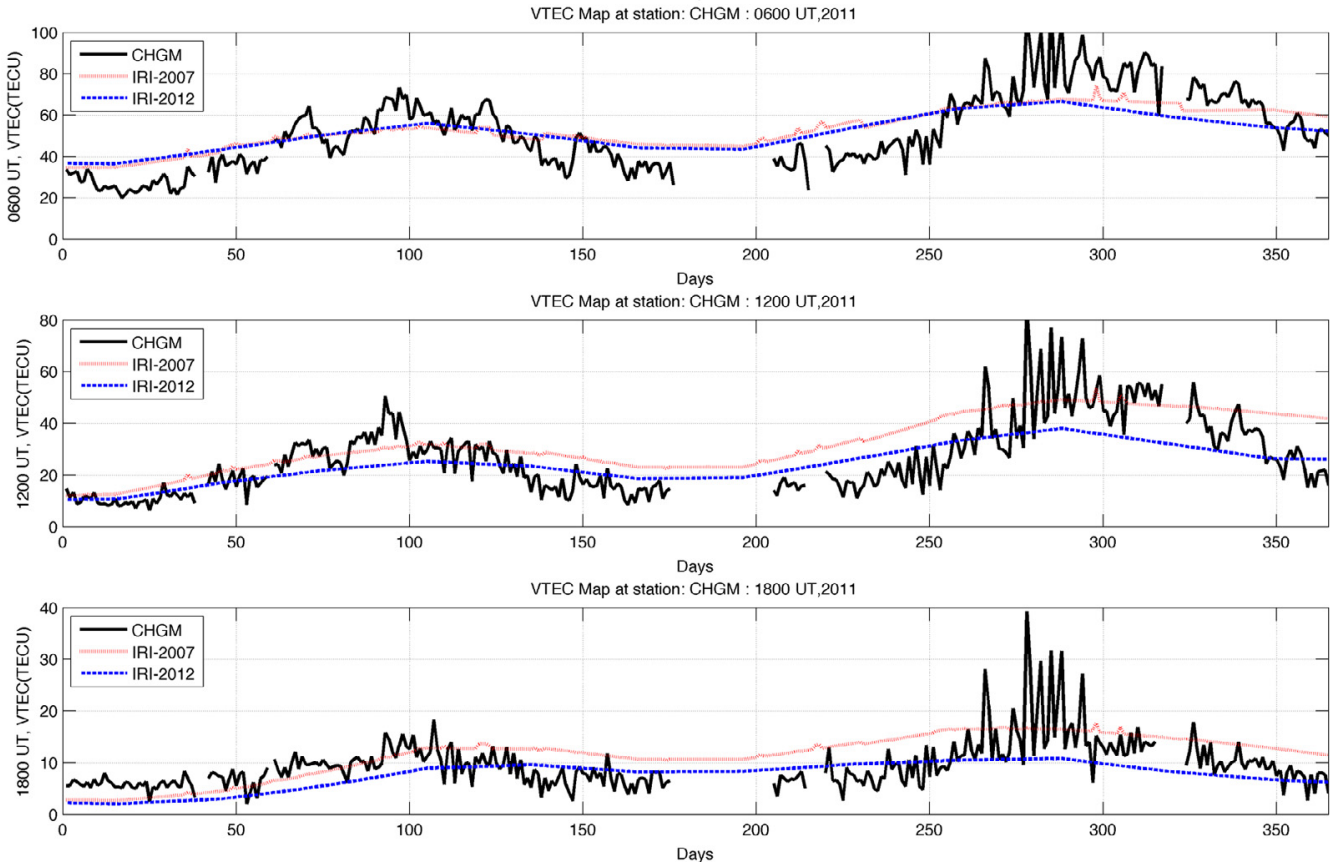

(b)
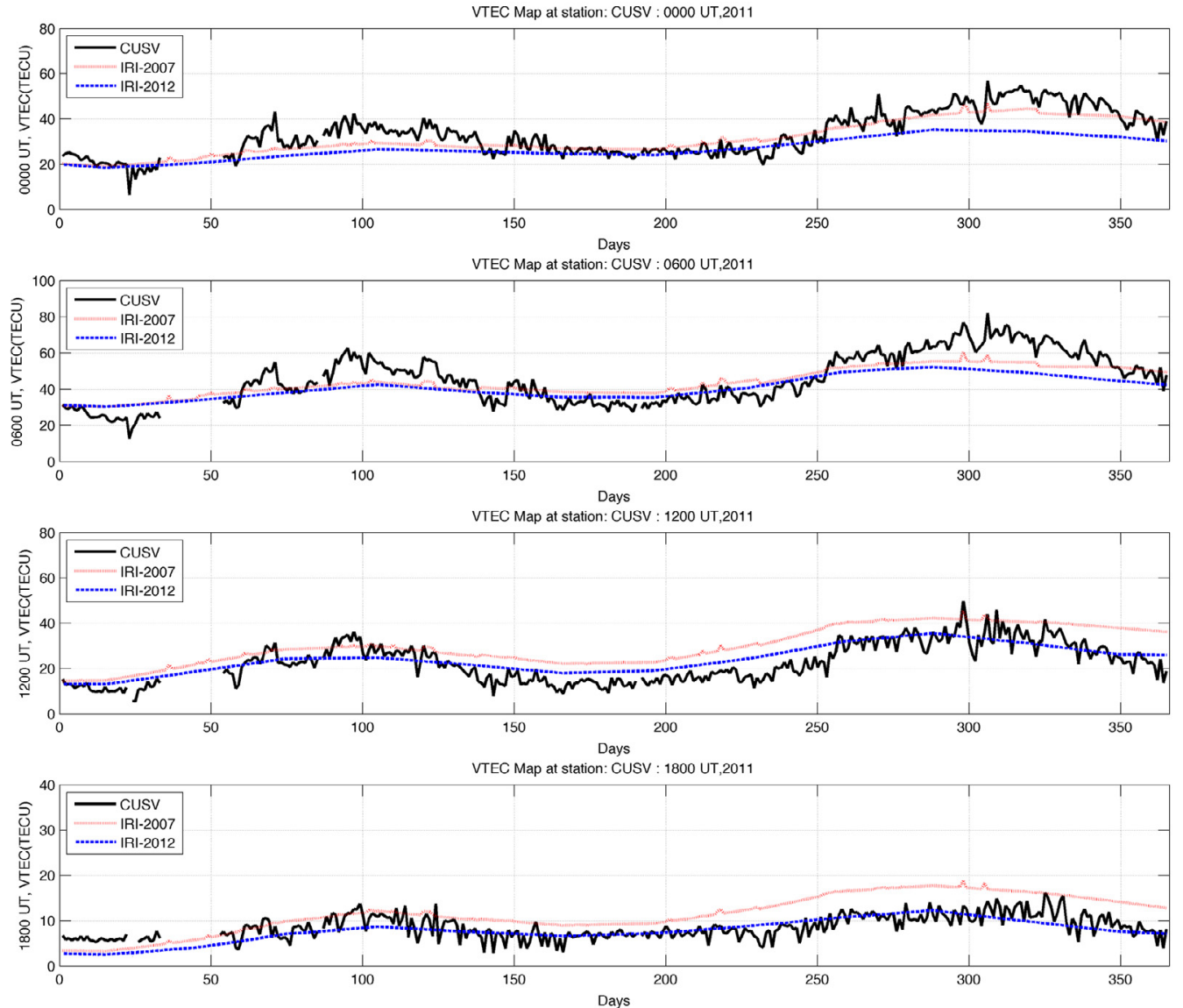

Figure 2. Mean variation of the GPS TEC, TEC from the IRI-2007 model and TEC from the IRI-2012 model, for the year 2011at CHGM and CUSV respectively sunrise, midday, post sunset and midnight. 
(a)
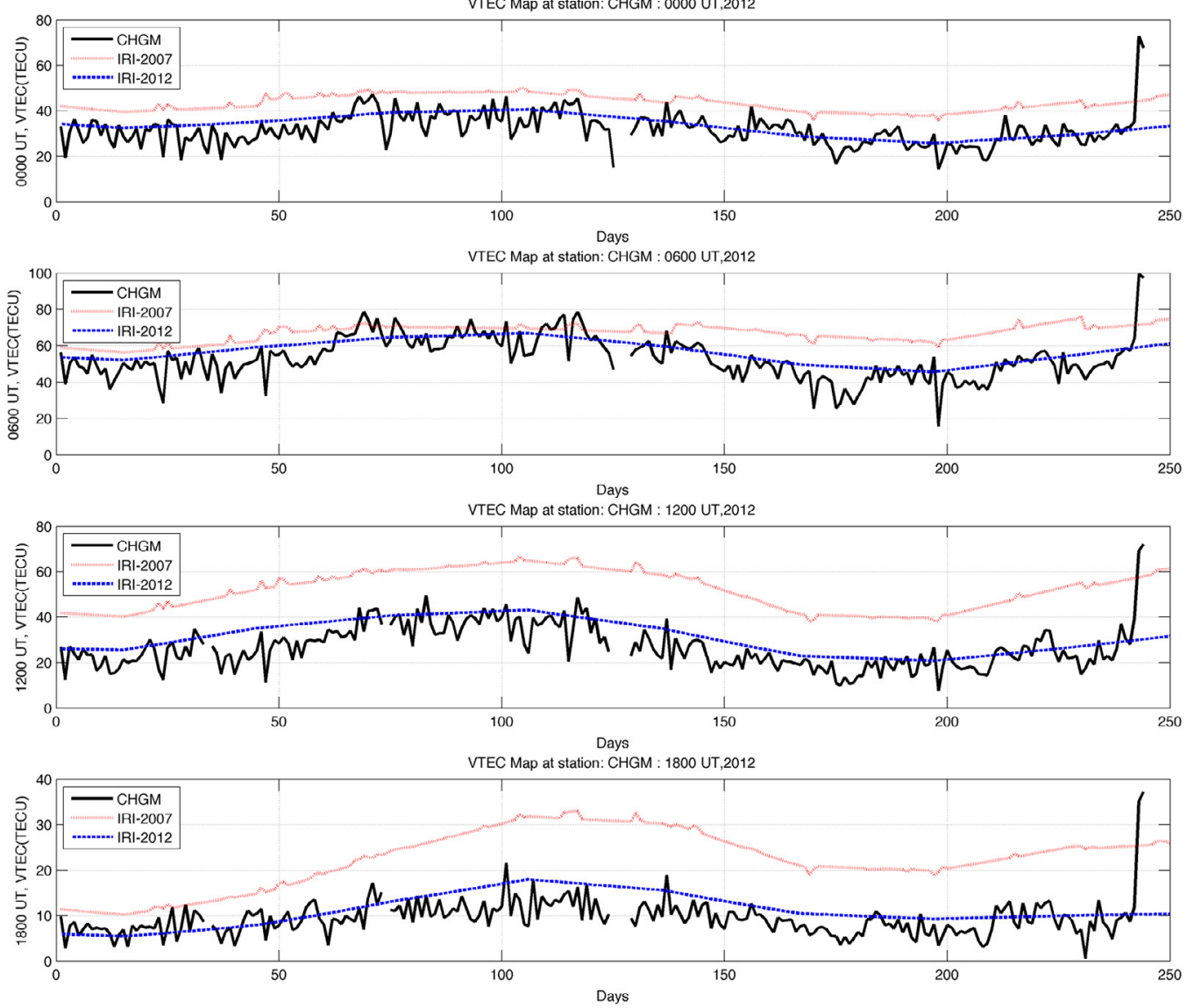

(b)
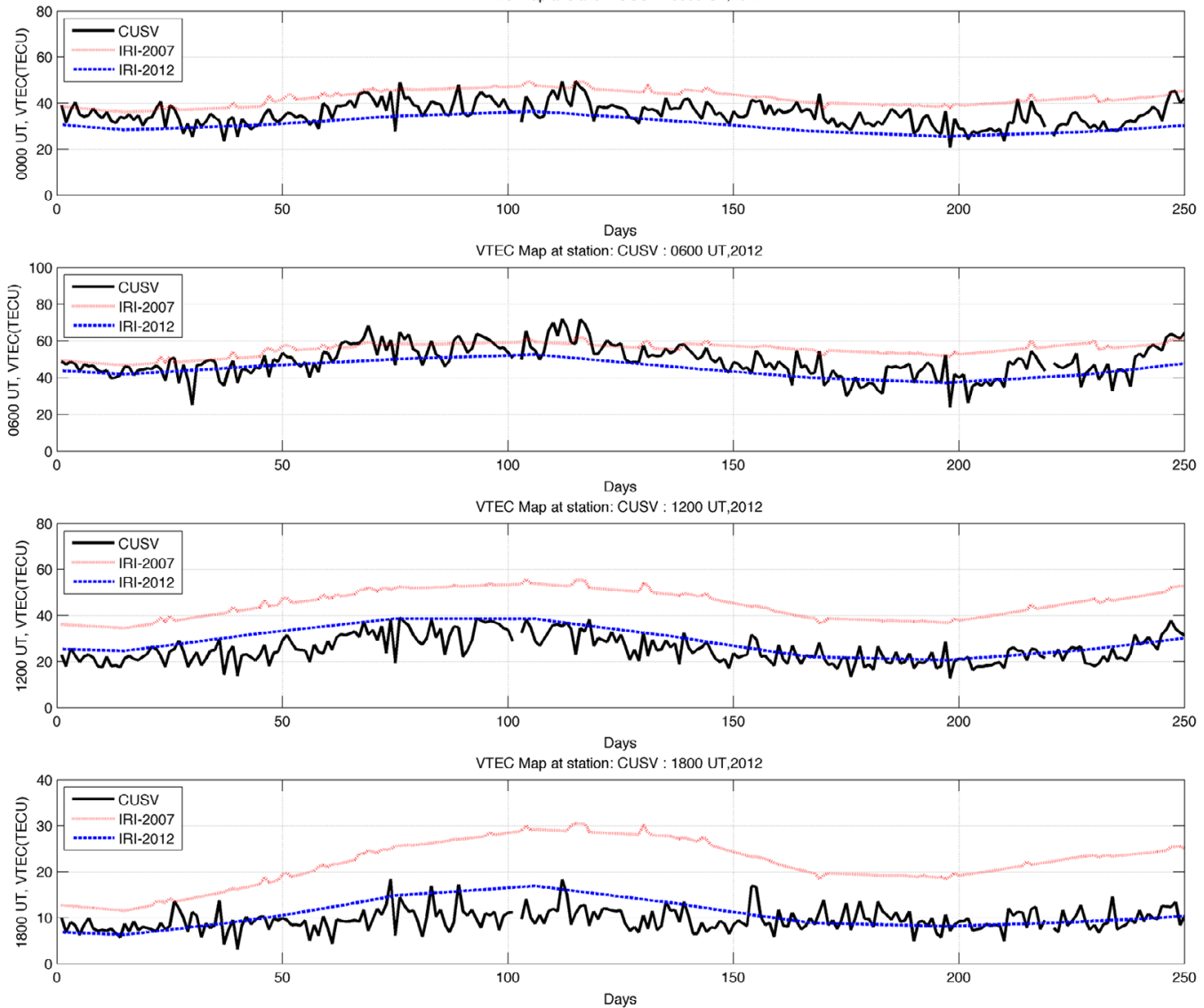

Figure 3. Mean variation of the GPS TEC, TEC from the IRI-2007 model and TEC from the IRI-2012 model, from January 2012 to August 2012 at CHGM and CUSV respectively sunrise, midday, post sunset and midnight. 

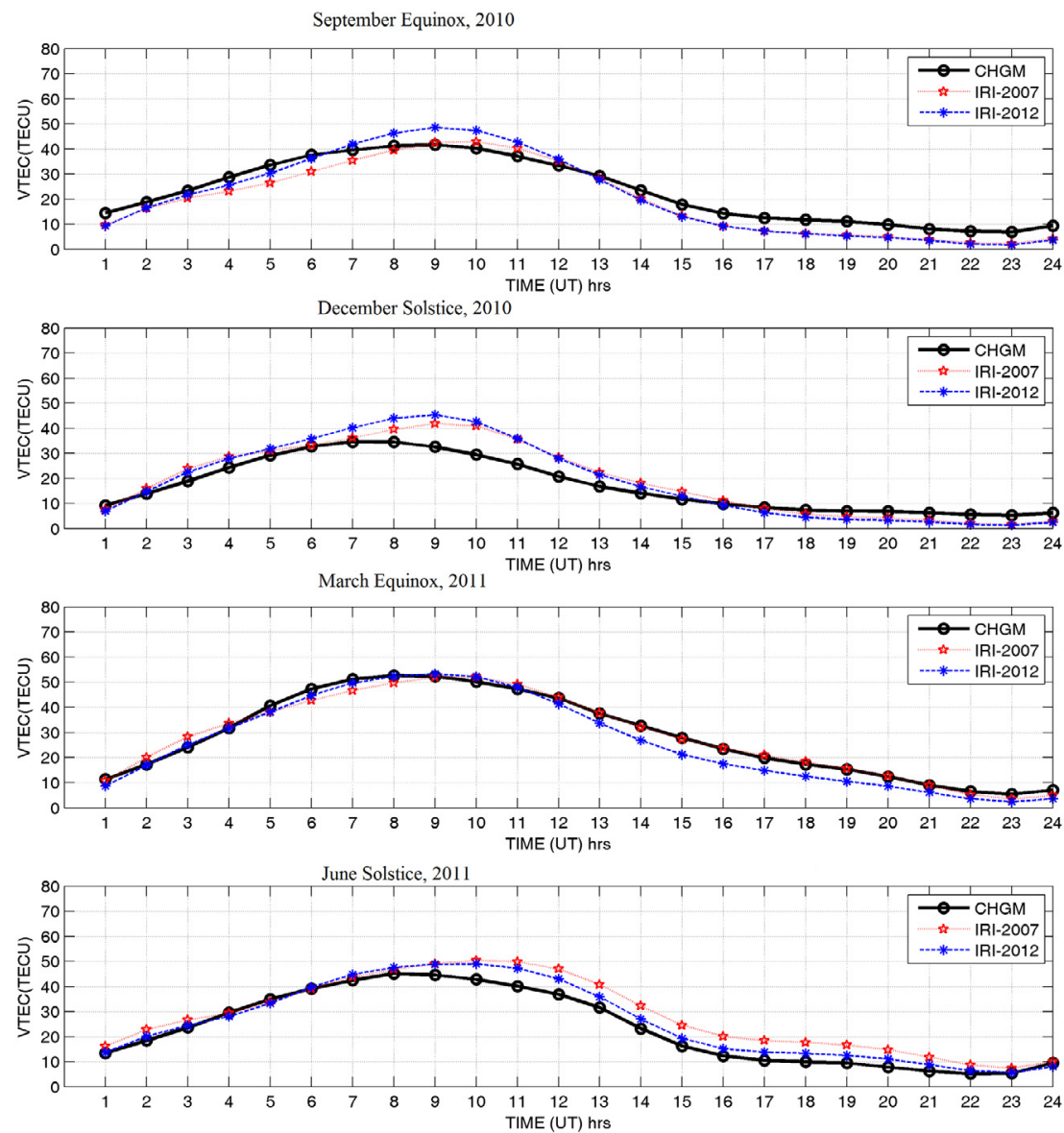

Figure 4. Seasonal mean values of GPS TEC, IRI-2007 TEC and IRI-2012 TEC at CHGM station for the period August 2010 - July 2011.
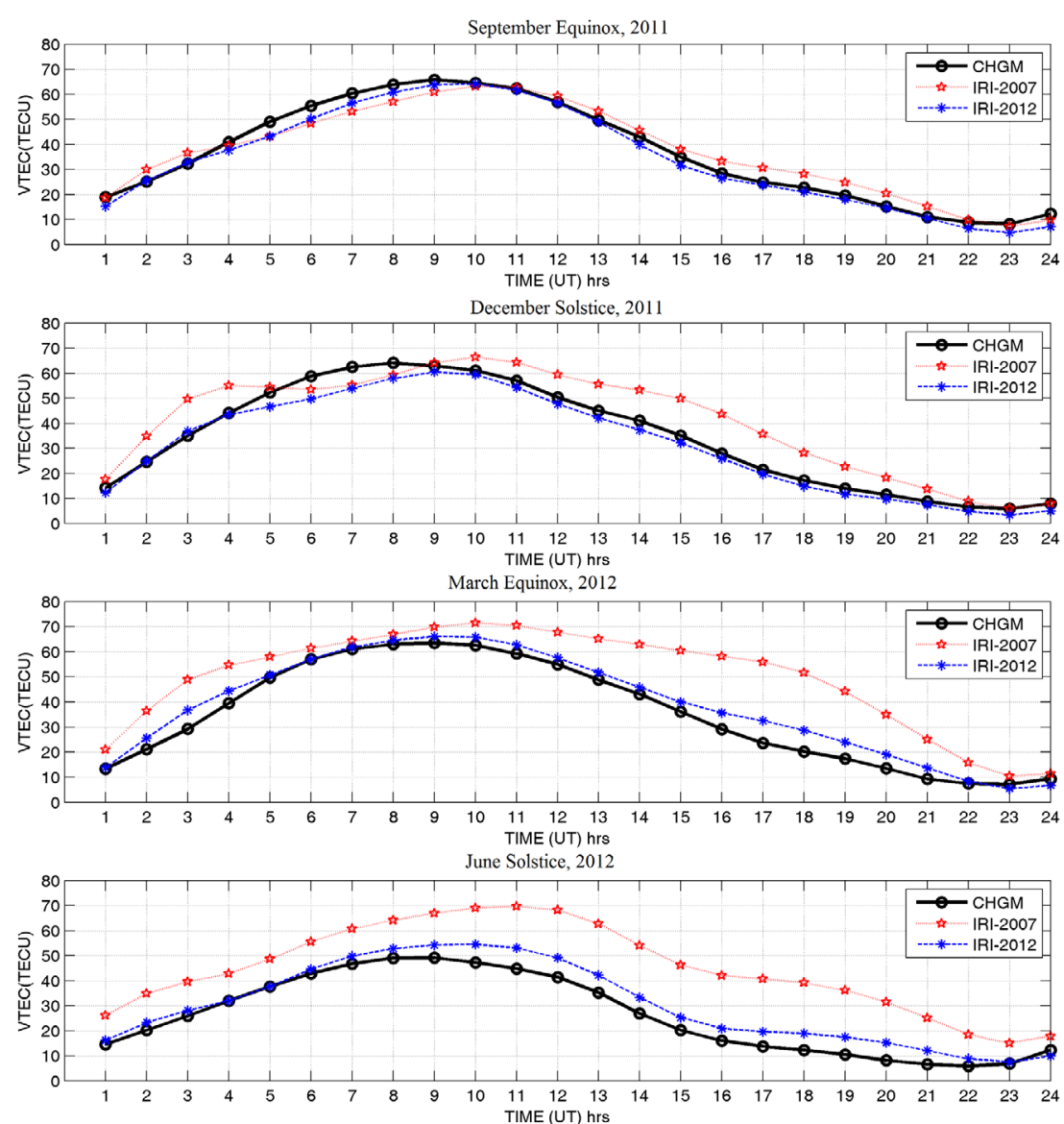

Figure 5. Seasonal mean values of GPS TEC, IRI-2007 TEC and IRI-2012 TEC at CHGM station for the period August 2011 - July 2012. 
seasonal plots it can be inferred that models fails to predict the noontime values and undergoes an overestimation. Data has shown more correlation with equinoctial months (ME and SE) than solstice months (DS and JS) during 0800 UT- 1300 UT.

Figure 5 shows that in SE 2011, IRI-2012 has shown good correlation with observed TEC data except an underestimation during 0400 UT to 0900 UT. For DS 2011, IRI-2007 has totally failed to predict the actual TEC values. Likewise SE 2011, IRI-2012 has shown good agreement with DS 2011. In ME 2012, IRI-2012 has shown little overestimation during 1500 UT to 2100 UT. Overall peak prediction of IRI-2012 has shown in agreement with GPS-TEC data. In JS 2012, IRI-2012 has overestimated the peak and has shown another smaller peak during 1900 UT. Thus, from all seasonal variations from 2010 - 2012, it can be inferred that TEC was more during equinox period than during solstice period, which is agreement with ealier studies. The long-term study of the seasonal maximum daytime VTEC at CHGM shows annual variation relative to upcoming solar cycle 24 and year 2012 being its peak.

\section{IGS station (CUSV):}

For the year 2010, we have two seasons namely September equinox 2010 and December solstice 2010. As seen from the figure IRI-2007 underestimates the TEC during 0400 UT to 0900 UT for September equinox (SE) 2010. IRI-2012 has followed almost same trend with IRI-2007 but with little less underestimation. The underestimation has being more evident at daytime than night time. During December solstice (DS) 2010, an overestimation by both models during 0800 UT to 1400 UT was clearly evident. Both models are higher by 8 TECU during sunset time and lower by 2 TECU during sunrise.

Figure 7 shows the mean values from all seasons for the year 2011. From the top panel of Figure 7 it is clearly visible that both models have underestimated TEC during noon time of March equinox (ME) 2011 and almost coinciding during night time. For June solstice (JS) 2011, both models have exhibited overestimation during $10 \mathrm{UT}$ - 22 UT i.e., from sunset to sunrise. September equinox (SE) 2011 can be observed as combination of both over and underestimations during post sunset to sunrise and noontime respectively. Thus from 2011 seasonal plots it can be inferred that models failed to predict the noontime values and undergoes an underestimation. Night time overestimation is mainly visible during JE 2011 and SE 2011.

Figure 8 shows seasonal mean values for the year 2012. Of all the data plots, year 2012 has shown intense variations in TEC. In ME 2012, IRI-2007 has totally failed predict the TEC values and IRI-2012 has underestimated during noon time and overestimated during nighttime. During ME 2012, peak observed by GPS TEC was $\sim 60$ TECU whereas IRI-2012 observed $\sim 52$ TECU as its peak. Two peaks were visible in IRI-2007 model which were not present in actual. For JS 2012, observed IGS GPS TEC and IRI-2012 were correlated well with a slight overestimation during nighttime. Observed peak was reduced to $\sim 45$ TECU.

Thus, from all seasonal variations, it can be inferred that TEC was more during equinox period than during solstice period, which is agreement with ealier studies. The large difference between the GPS-TEC and IRI TEC during noontime indicates that the ionosphere at low-latitude or the equatorial area is expanded to cover a larger thickness than at other times. At the equatorial latitude, the steepest gradients, sharp peaks and deep valleys, and density crests are on both sides of the equator, as explained by Bilitza and Reinisch et al. [2008]. The occurrence of a prominent trough accompanied by maximum TEC values in the pre-noon and the afternoon at equatorial latitudes is referred to as a noon bite-out, which is a characteristic feature at an
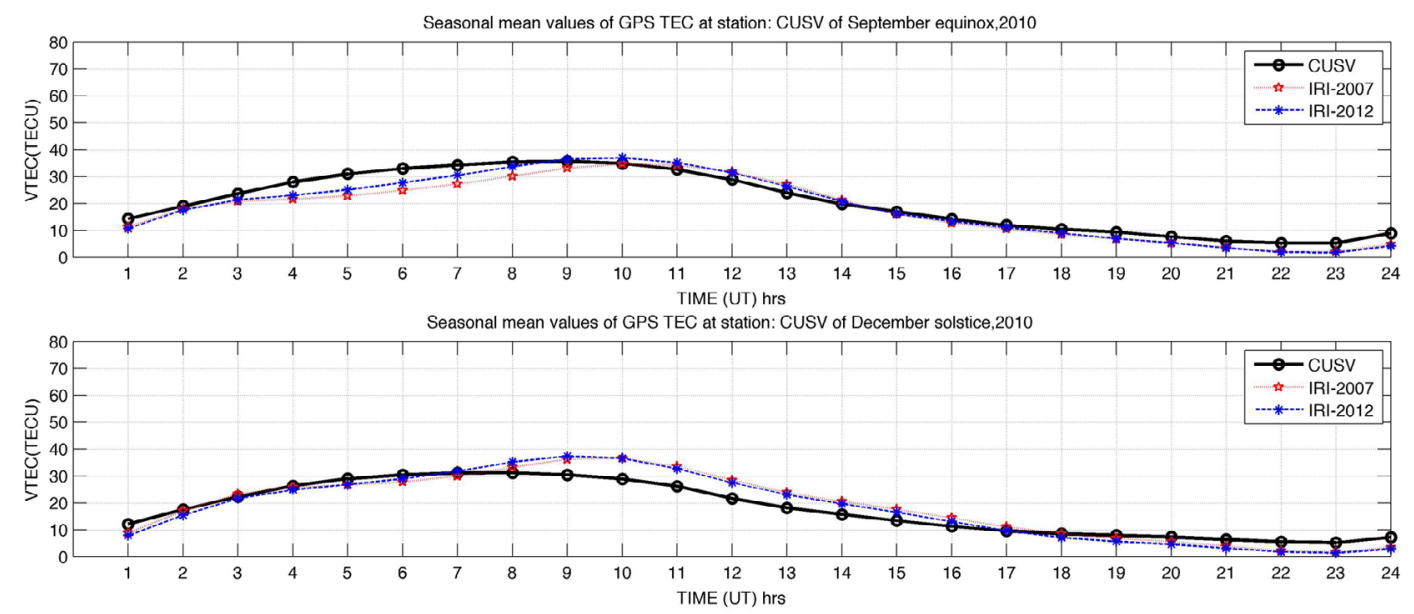

Figure 6. Seasonal mean values of GPS TEC, IRI-2007 TEC and IRI-2012 TEC at CUSV station during the period 2010. 

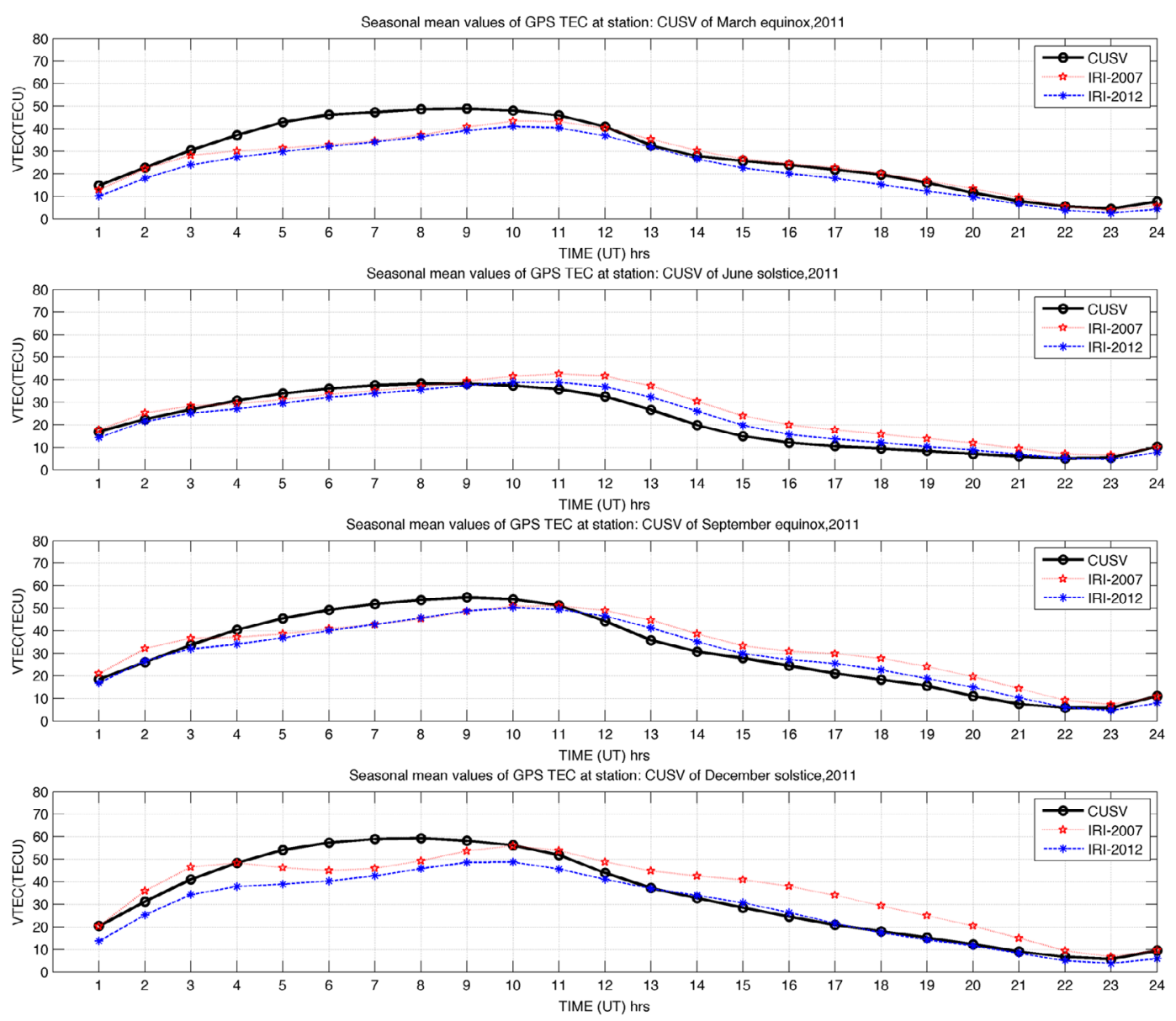

Figure 7. Seasonal mean values of GPS TEC, IRI-2007 TEC and IRI-2012 TEC at CUSV station during the period 2011.
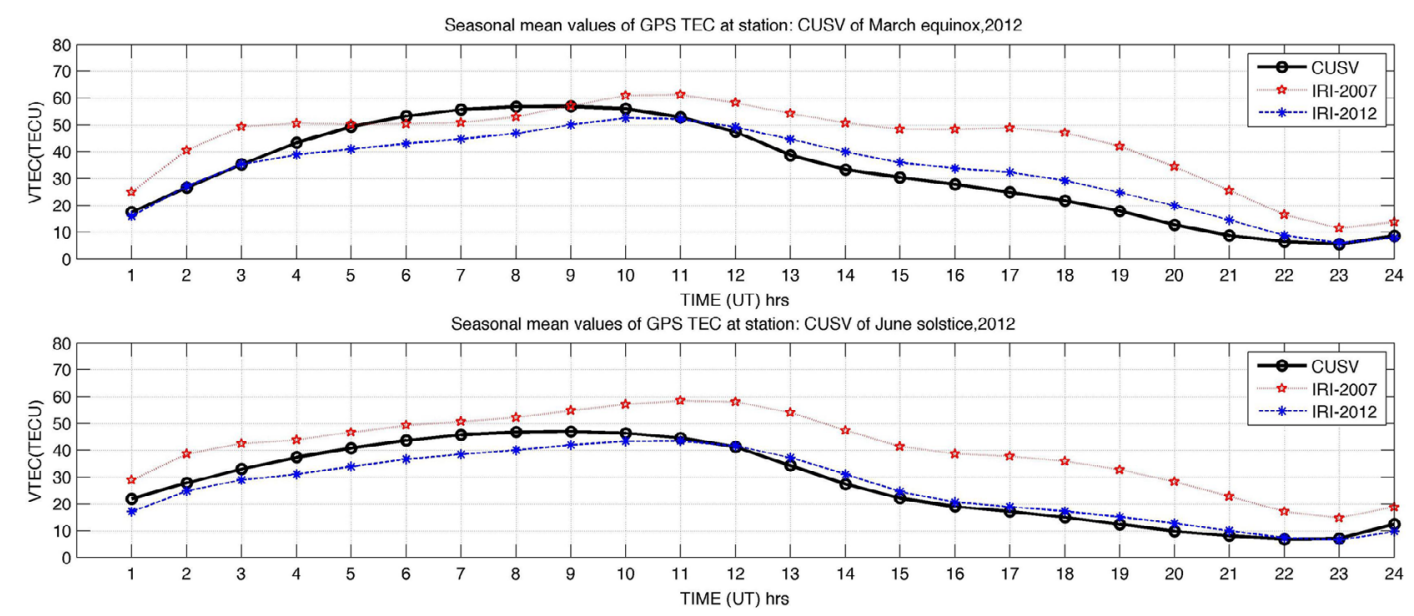

Figure 8. Seasonal mean values of GPS TEC, IRI-2007 TEC and IRI-2012 TEC at CUSV station during the period 2012.

equatorial station that falls in the trough of the equatorial anomaly [Maeda 1955, Rastogi 1959]. The noon bite-out phenomenon is the result of interaction and the relative role played by the production, loss, and movements terms in the continuity equation of the electron density at the peak of the layer. TEC movement includes the effects of vertical drift, horizontal diffusion of ionization along the field lines, and neutral winds. Martyn [1955] and Rao [1966] showed that the pre-noon peak in the diurnal variation at equatorial latitudes is influenced by horizontal winds in addition to production and loss processes, while the afternoon peak is determined by vertical drifts and diffusion. The semiannual anomaly of the diurnal VTEC observed at CUSV station with maximum values at the equinoxes is similar to the observations from equatorial, low and high latitudes [Dashora and Pandey 2005, Kumar et al. 2012, Olwedo et al. 2012, Spogli et al. 2013]. 


\subsection{Monthly variations in GPS-TEC for both the sta-} tions

In this section we have compared the GPS-TEC variations for the both stations for the period July 2010 to August 2012. Figure 9 shows the comparison between the measured mean GPS-TEC from both stations for the period 2010. The observations of monthly variations of TEC from both stations are based on 6 months of GPS-TEC data for the year 2010. The monthly mean values deduced from the daily values and the observed GPS-TEC has been compared and analysed for both stations. The monthly mean GPS-TEC for all the months in 2010 are given in TEC units (TECU) on the vertical axis, and the horizontal axis represents time in UT (local time, LT $=\mathrm{UT}+7 \mathrm{~h}$ ). It can be observed from the plots of Figure 9, that GPS-TEC values observed at CHGM are comparatively higher than the GPS-TEC values observed at CUSV. It can be inferred that trends of both station's GPS-TEC were almost similar. Highest differences in TEC values can be observed during the month of October 2010. This can be due to EIA effect observed in the equatorial latitude stations. Peak TEC values observed are up to $\sim 40$ TEC during the months of the year 2010 for CUSV station.

In the year 2011, the GPS-TEC values have shown an increasing trend. For January observed peak GPSTEC values were $\sim 30$ TECU from both stations, whereas for October this peak has raised to $\sim 60$ TECU and $\sim 80$ TECU for CUSV and CHGM stations respec- tively. Due to expected solar maximum an increase in the solar activities were quite evident and the sunspot number has rise from 19 in January to about 97 in November 2011. This has resulted in increase in TEC values throughout the year. Comparing maximum total electron content values obtained at both stations for all months of 2011 shows that CHGM station recorded higher TEC values than CUSV station.

In the year 2012, the GPS-TEC values have shown increasing trend due to upcoming solar cycle 24 . It can be observed that months of equinox were having higher values of TEC than compared with solstice months. Highest differences in TEC values were exhibited during March, April and August months for both stations. Number of severe events has also influenced the sudden increment in TEC values during March 2012 at both stations. From all the year data, it can be inferred that during equinox period variations between stations were much higher than during solstice period. The observed higher TEC values at CHGM can be due to formation of ionization crest exactly above the CHGM station. Due to CHGM station is placed at higher latitude than CUSV it is affected by the fountain effect. And it has been observed that CHGM's TEC values ranges from $\sim 5$ TECU to 15 TECU during solstice to equinox accordingly, when compared with CUSV's TEC values. It can be inferred that of both stations data that the case of TEC varies as one move away from the equatorial region.
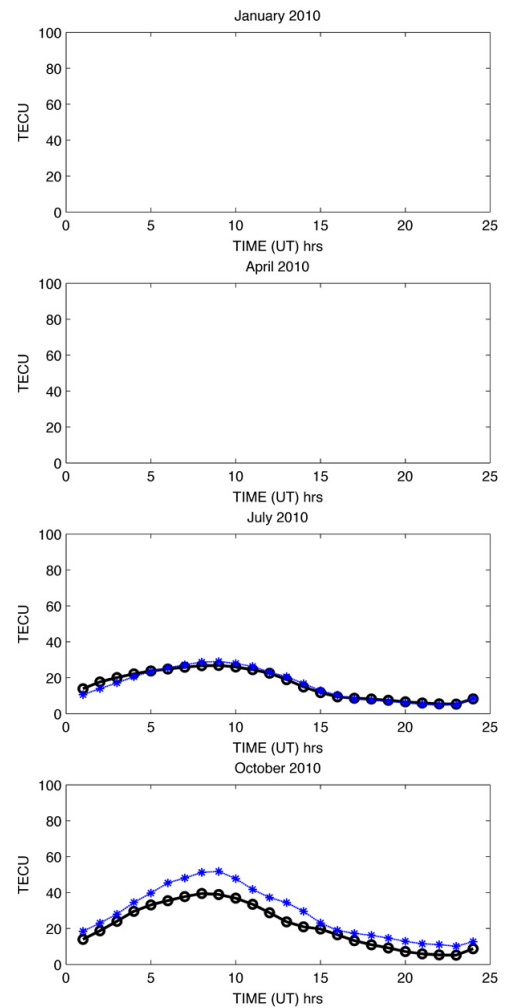
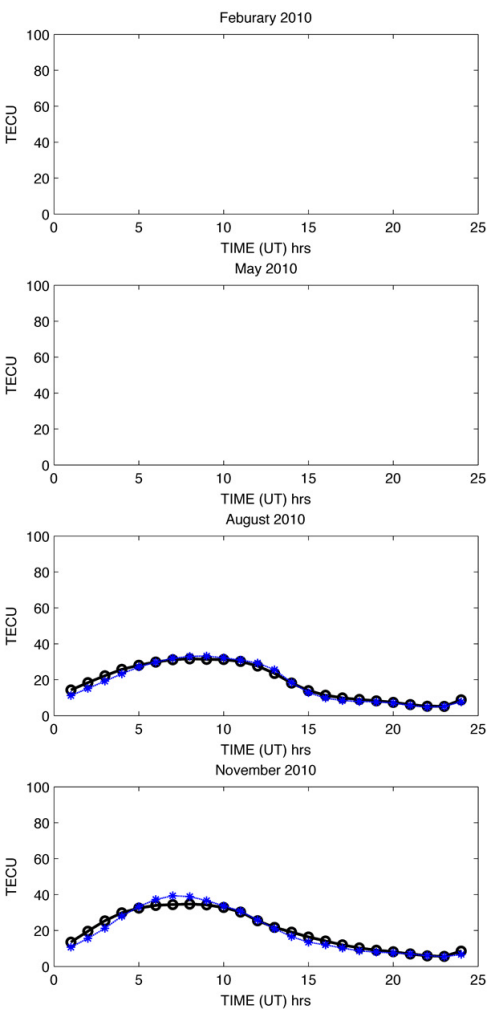
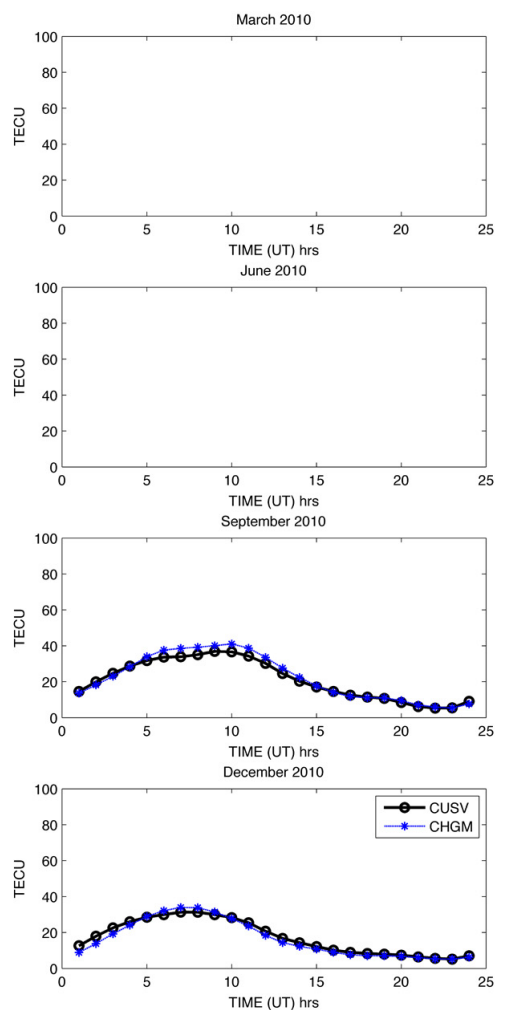

Figure 9. Comparison of monthly variations of mean GPS TEC values at CHGM and CUSV stations during the period 2010. 

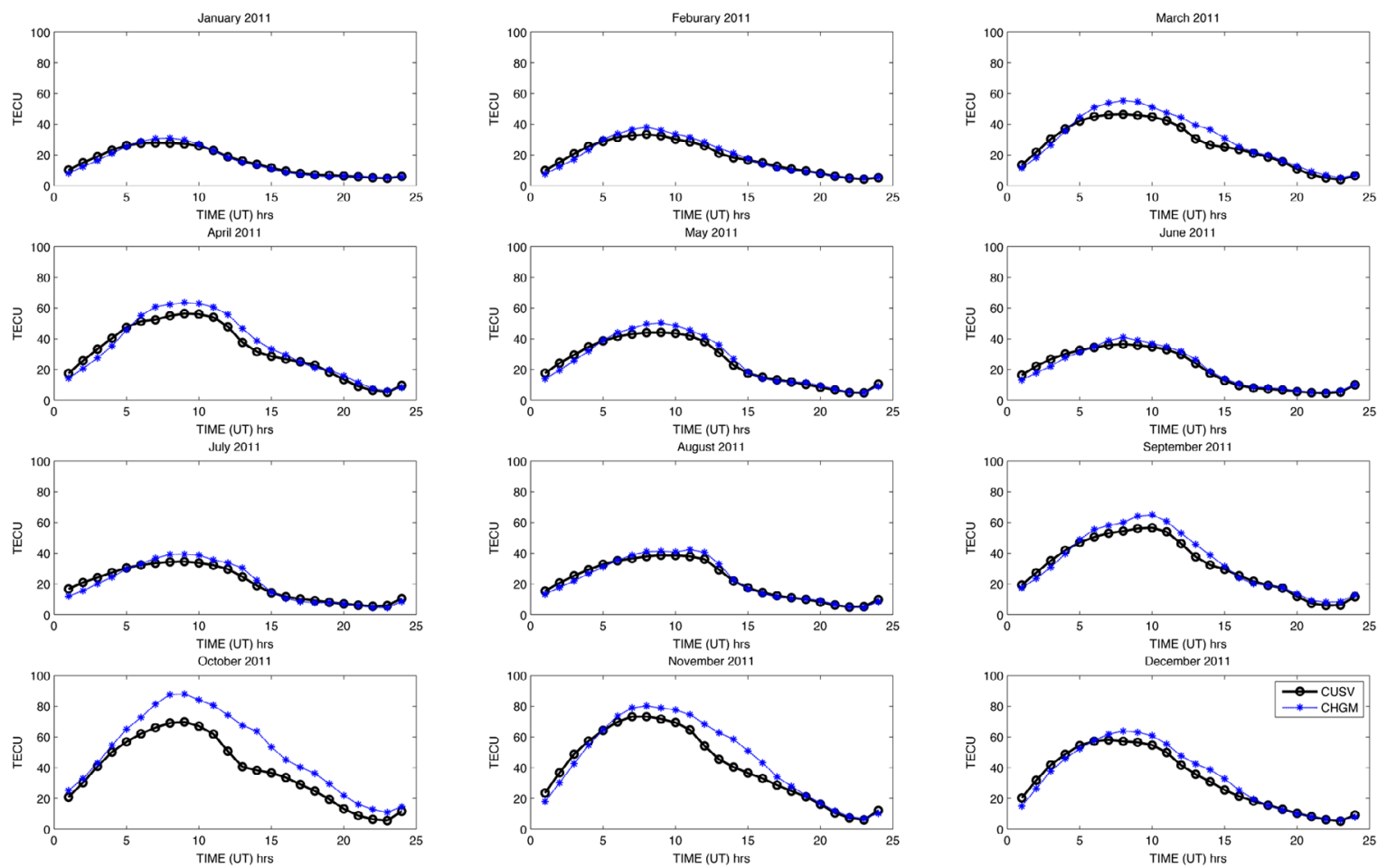

Figure 10. Comparison of monthly variations of mean GPS TEC values at CHGM and CUSV stations during the period 2011.
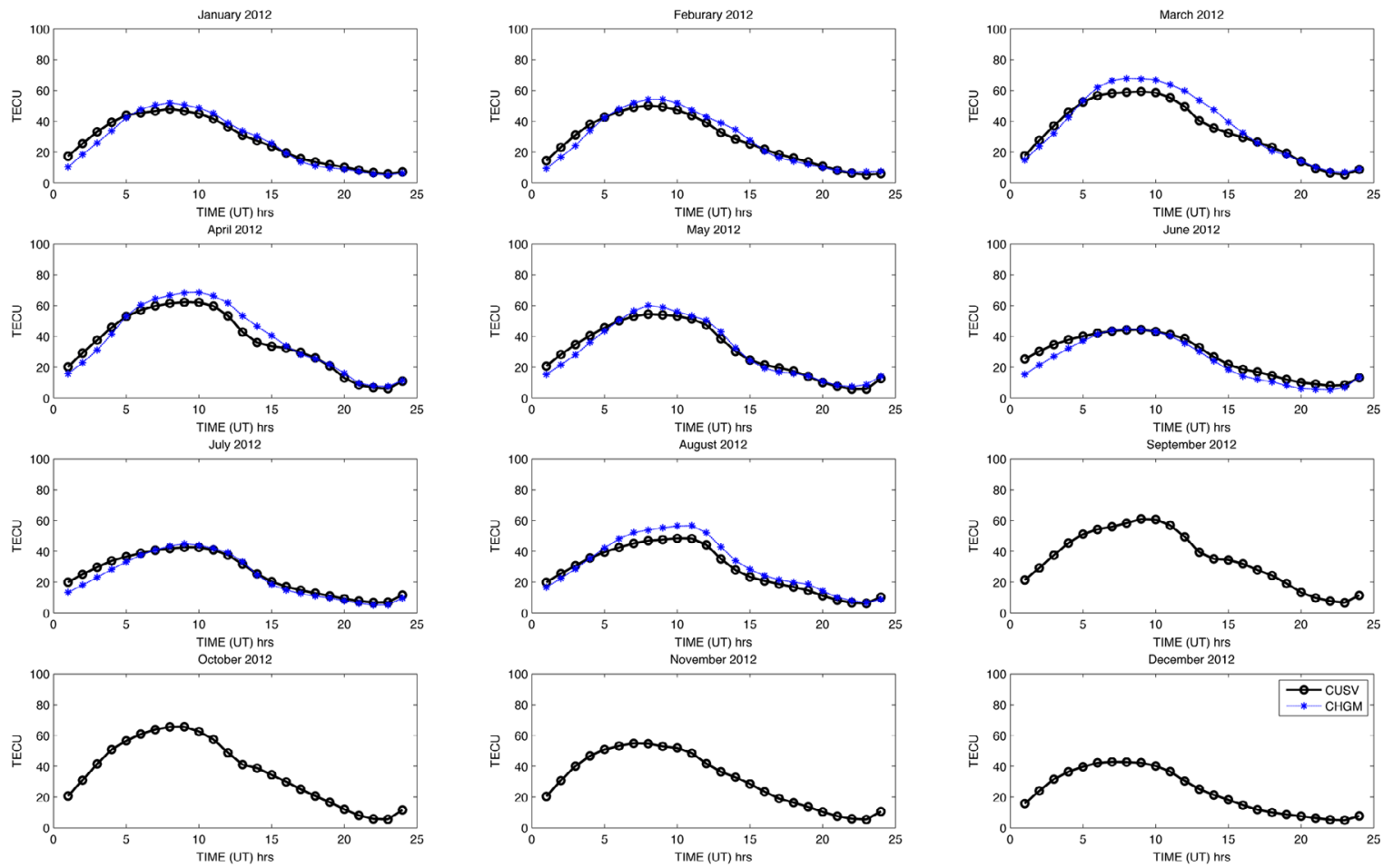

Figure 11. Comparison of monthly variations of mean GPS TEC values at CHGM and CUSV stations during the period 2012.

\section{Conclusion}

In this work, the GPS TEC derived from the TEC data at Chiang Mai and IGS equatorial stations, in Thailand were compared with the IRI-2007 TEC and IRI2012 TEC from August 2010 to July 2012. The maximum differences with IRI models are about 15 TECU during the daytime and about 5 TECU during the night time.
When compared with the IRI-2007, we find that the GPS-TEC measurements from the both stations are quite similar, and both are in good agreement than the TEC predicted for the year 2010. Although an overestimation and underestimation was quite evident during local noon time and early morning hours for both stations respectively. For the year 2011, an underestimation 
and overestimation during equinox and solstice period respectively was quite eveident. And for the year 2012, IRI-2007 model totally failed to predict the TEC values. The differences ranging from 5 to 15 TECU were observed to be found between IRI-modeled values and that of GPS-TEC. With IRI-2012, the overestimation is more apparent at noontime than night time, particularly during the noon bite-outs. This difference during daytime indicates that it is due to the difference of slab thickness in the ionosphere between the IRI model and the measured data. Also, it has to be noted that GPS calculated TEC includes plasmapheric TEC as well whereas IRI calculated TEC is upto $2000 \mathrm{~km}$ height only.

For the year 2012, the IRI-2012 model has shown a higher positive correlation for 2012 than for previous years. Thus it can be inferred that performance of the model depends on the year of the data chosen for the data validation. It is recommended to use IRI-2012 model for the data from the year 2012 onwards than IRI-2007. Normally, it is observed that IRI-2007 has good agreement with the 2010 to 2011 year's data from both stations and IRI-2012 has shown good correlation with data from 2012 onwards than IRI-2007 for data validation of TEC. Two shortfalls were however noted about the predictability of the IRI-2012 for the measured values of the diurnal variation of TEC at these equatorial stations: The model overestimates the night time TEC for the year 2012 and overestimates TEC during solstice period for the year 2011; and IRI-2012 model generally remains smooth and underestimates TEC during a storm period. This gives the importance of in-situ station monitoring of equatorial ionospheric anomaly to capture local anomalies.

The results have shown that the highest ionospheric TEC occurred from 1500 LT to 1900 LT throughout the study period, with the highest values being exhibited by the equinoctial months, while the lowest values by the solstice months. In addition, the months of March, May, August, September and October, which had moderate storm days, show higher TEC values than the months of June and July which exhibited quiet conditions during 2011. And TEC was higher during 2012 due to expected solar cycle 24 peak. The observed high GPS-TEC values have been attributed to the solar EUV ionization coupled with the upward vertical $\mathrm{E} \times \mathrm{B}$ drift [Bolaji et al. 2012].

Due to formation of ionization crest over the CHGM station, it has experienced higher values of TEC than CUSV station for the study period. CHGM station being at higher latitude than CUSV, it is pronounced to get more experience of fountain effect. And it can be been observed from the data that CHGM's TEC values ranges from $\sim 5$ TECU to 15 TECU during solstice to equinox accordingly, when compared with CUSV's TEC values. That means variation in equinox is much more prominent than that during solstice months.

Acknowledgements. The authors would like to express their gratitude to GPS-SCINDA stations authorities for installing various stations in Thailand and providing access to data. And we express gratitude to NASA's Goddard Space Flight Center for hosting IRI models and for providing access to important data for comparison and data analysis. Also, we would like to credit the IGS network for providing access to worldwide data of GPS. This work has been executed as a part of the Local Ionospheric Scintillation Analysis (LISA) project. We would like to thank the reviewers of this paper for their constructive comments.

\section{References}

Adewale, A.O., E.O. Oyeyemi, P.J. Cilliers, L.A. McKinnell and A.B.Adeloye (2012). Low solar activity variability and IRI 2007 predictability of equatorial Africa GPS TEC, Adv. Space Res., 49, 316-326.

Appleton, E.V. (1946). Two anomalies in the ionosphere, Nature, 157, 691.

Arunpold, S., N.K. Tripathi, V.R. Chowdhary and D.K. Raju (2014). Comparison of GPS-TEC measurements with IRI-2007 and IRI-2012 modeled TEC at an equatorial latitude station, Bangkok, Thailand, J. Atmos. Terr. Phys., 117, 88-94.

Bhattacharya, S., P.K. Purohit and A.K. Gwal (2009). Ionospheric time delay variations in equatorial anomaly region during low solar activity using GPS, Indian J. Radio Space Phys., 38, 266-274.

Bhuyan, P.K., and R.R. Borah (2007). TEC derived from GPS network in India and comparison with the IRI, Adv. Space Res., 39, 830-840.

Bilitza, D., M. Hernandez-Pajares, J.M. Juan and J. Sanz (1998). Comparison between IRI and GPS-IGS derived electron content during 1991-97: first results, Phys. Chem. Earth, 24 (4), 311-319.

Bilitza, D. (2003). International Reference Ionosphere 2000: Examples of improvements and new features, Adv. Space Res., 31, 151-167.

Bilitza, D., and B.W. Reinisch, (2008). International Reference Ionosphere 2007: Improvements and new parameters, Adv. Space Res., 42, 599-609.

Bolaji, O.S., J.O. Adeniyi, S.M. Radicella and P.H. Doherty (2012). Variability of total electron content over an equatorial West African station during low solar activity, Radio Sci., 47; http:/ / dx.doi.org/10. 1029/2011RS004812.

Carrano, C., and K. Groves (2006). The GPS Segment of the AFRL-SCINDA Global Network and the Challenges of Real-Time TEC Estimation in the Equatorial Ionosphere, ION NTM 2006 (Monterey, CA, January 18-20), 1036-1047.

Chauhan, V., and O.P. Singh (2010). A morphological 
study of GPS-TEC data at Agra and their comparison with the IRI model, Adv. Space Res., 46, 280-290.

Chowdhary, V.R., N.K. Tripathi, S. Arunpold and D.K. Raju (2015). Variations of total electron content in the equatorial anomaly region in Thailand, Adv. Space Res., 55 (1), 231-242; doi:10.1016/j.asr.2014. 09.024 .

Correia, E., A.J. Paz and M.A. Gende (2013). Characterization of GPS total electron content (GPS-TEC) in Antarctica from 2004 to 2011, Annals of Geophysics, 56 (2), R0217.

Dashora, N., and R. Pandey (2005). Observations in equatorial anomaly region of total electron content enhancements and depletions, Annales Geophysicae, 23, 2449-2456.

D’ujanga, F.M., J. Mubiru, B.F. Twinamasiko, C. Basalirwa and T.J. Ssenyonga (2012). Total electron content variations in equatorial anomaly region, Adv. Space Res., 50, 441-449.

Ezquer, R., C. Brunini, M. Mosert, A. Meza, R. del V. Oviedo, E. Kiorcheff and S.M. Radicella (2004). GPS-VTEC measurements and IRI predictions in the South American sector, Adv. Space Res., 34, 2035-2043.

Huang, X., and B.W. Reinisch (2001). Vertical electron content from ionograms in real time, Radio Sci., 36 (2), 335-342.

Jakowski, N., E. Sardon and S. Schluter (1998). GPSBased TEC observations in comparison with IRI95 and the European TEC model NTCM2, Adv. Space Res., 22 (6), 803-806.

Jodogne, J.C., H. Nebdi and R. Warnant (2004). GPS TEC and ITEC from digisonde data compared with NEQUICK model, Adv. Sapce Res., 2, 269-273.

Kumar, S., S. Priyadarshi, S.G. Krishna and A.K. Singh (2012). GPS-TEC variations during low solar activity period (2007-2009) at Indian low latitude stations, Astrophys. Space Sci., 339, 165-178; doi:10.1007/s10 509-011-0973-6.

Luhr, H., and C. Xiong (2010). IRI-2007 model overestimates electron density during the 23/24 solar minimum, Geophys. Res. Lett., 37, L23101.

Maeda, H. (1955). Horizontal Wind Systems in the Ionospheric $E$ Region Deduced from the Dynamo Theory of the Geomagnetic $S_{q}$ Variation. Part I: Nonrotating Earth, J. Geomagn. Geoelectr., 7, 121-132.

Martyn, D.F. (1955). The Physics of the Ionosphere, The Physical Society, London, $260 \mathrm{p}$.

Mendes da Costa, A., J.W.V. Boas and E.S. da Fonseca Junior (2004). GPS total electron content measurement at low latitudes in Brazil for low solar activity, Geofis. Int., 43 (1), 129-137.

Mosert, M., R. Ezquer, C. Jadur and R. del V. Oviedo
(2004). Time variation of total electron content over Tucuma, Argentina, Geofis. Int., 43 (2), 143-151.

Mosert, M., M. Gende, C. Brunini, R. Ezquer and D. Altadill (2007). Comparisons of IRI TEC predictions with GPS and digisonde measurements at Ebro, Adv. Space Res., 39, 841-847.

Olwendo, J.O., P. Baki, P.J. Cilliers, C. Mito and P. Doherty (2012). Comparison of GPS TEC measurements with IRI-2007 TEC prediction over the Kenyan region during the descending phase of solar cycle, Adv Space Res., 49, 914-921.

Opperman, B.D.L., P.J. Cilliers, L.A. McKinnel and R. Haggard (2007). Development of a regional GPSbased ionospheric TEC model for South Africa, Adv Space Res., 39, 808-815.

Rao, B.C.N. (1966). Control of equatorial Spread-F by the F layer height, J. Atmos. Terr. Phys., 28, 12071217.

Rastogi, R.G. (1959). The diurnal development of the anomalous equatorial belt in the F2 region of the ionosphere, J. Geophys. Res., 64, 727-732.

Scida, L.A., R.G. Ezquer, M.A Cabrera and M. Mosert (2009). IRI 2001/90 TEC predictions over a low latitude station, Adv. Space Res., 44, 736-741.

Seemala, G.K., and C.E. Valladares (2008). Statistics of total electron content depletions observed over the South American continent for the year 2008, Radio Sci., 46, RS5019; http:/ / dx.doi.org/10.1029/2011RS 004722 .

Sethi, N.K., R.S Dabas and S.K. Sarkar (2011). Validation of IRI-2007 against TEC observations during low solar activity over Indian sector, J. Atmos. Terr. Phys., 73, 751-759.

Spogli, L., L. Alfonsi, P.J. Ciliers, E. Correia, G. D. Franceschi, C.N. Mitchell, V. Romano, J. Kinrade and M.A. Cabrera (2013). GPS scintillations and total electron content climatology in the southern low, middle and high latitude regions, Annals of Geophysics, 56 (2), R0220.

Xu, Z., W. Weimin, Z. Nan, S. Xiaofei and Z.U. Haotian (2012). Variability study of ionospheric total electron content at crest of equatorial anomaly in China from 1997 to 2007, Adv. Space Res., 50 (1), 70-76.

\footnotetext{
Corresponding author: V. Rajesh Chowdhary,

Asian Institute of Technology, School of Engineering and

Technology, Klong Laung, Pathumthani, Thailand;

email: rajesh.vattikuti@gmail.com,vrajeshc@ait.asia.

C 2015 by the Istituto Nazionale di Geofisica e Vulcanologia. All rights reserved.
} 